\title{
Simulation and Prediction of the Groundwater Pollution Caused by the Leakage from a Sewage Plant in an Aluminum Factory Under the Action of Ocean Tide Support
}

\author{
$\mathrm{Yu}$ ZHANG and Junkang LAN ${ }^{1}$ \\ College of Environmental Science and Engineering, Guilin University of Technology, \\ Guilin 541004, China
}

\begin{abstract}
In order to predict the impact of wastewater from an aluminum plant treatment station on the groundwater environment under abnormal conditions (i.e., sewage leakage accident). Through the investigation of hydrogeological conditions, and then the permeability coefficient of the aquifer was measured through borehole injection tests. Finally, the groundwater pollution transport halo was obtained by numerical simulation based GMS software. The simulation results showed that the groundwater aquifer will be seriously polluted by COD and fluoride (F-) after the sudden sewage seepage accident. What's more, the simulation results showed that the pollution concentration is getting higher and higher with time, which is analyzed to be caused by the small permeability of the water-bearing medium in the aquifer and the groundwater flow field was supported by seawater tide.
\end{abstract}

Keywords. Groundwater pollution, sudden sewage seepage accident, ocean tide

\section{Introduction}

The simulation of contaminant transport in coastal aquifer is always a difficult problem [1-2], because not only the disturbance of seawater quality, but also the retardation effect of tide jacking on groundwater velocity should be considered in the simulation. An aluminum production base is proposed to be built on the Qisha Peninsula in Guangxi. Before its construction, it is necessary to predict the impact of the project on the surrounding groundwater environment and the migration speed and direction of the pollutants under "abnormal conditions" (i.e., sudden leakage), so that people can take scientific preventive measures before the leakage, and effectively prevent the harm of groundwater pollution.

${ }^{1}$ Corresponding Author, Junkang LAN, College of Environmental Science and Engineering, Guilin University of Technology, Guilin 541004, China; Email:1269431898@ qq.com 


\section{Hydrogeological Conditions of the Study Area}

The project is located in Qisha Town, Fangchenggang City, Guangxi Province, and the landform of the study area is mainly erosion accumulation plain, with elevations ranging from -0.5 to $31 \mathrm{~m}$. The area is also located in a humid, hot, and rainy subtropical monsoon climate zone and the average annual rainfall is $2401.2 \mathrm{~mm}$.

The sea tide in the study area belongs to diurnal tide, which is characterized by high and low tides twice a day for about 2-4 days. Small tide period, maximum tide difference $5.56 \mathrm{~m}$, average tide difference $2.39 \mathrm{~m}$.

There are three aquifers in the study area: (1) Gravel pore aquifer in Quaternary modern marine sedimentary layer $\left(\mathrm{Q}_{4-2}{ }^{\mathrm{m}}\right)$. Its lithology is mainly sandy silt and muddy sand. (2) Porous fractured aquifer $\left(\mathrm{J}_{1}\right)$. Its lithology is siltstone, mudstone with fine sandstone, mudstone with siltstone, quartz sand, glutenite, etc. (3) Fractured aquifer $\left(\mathrm{S}_{1} \ln \right)$. Its lithology is argillaceous sandstone with siltstone in the upper part, argillaceous sandstone, and siltstone interbedding in the middle part and argillaceous sandstone in the lower part.

The groundwater in the study area is mainly supplied by atmospheric rainfall, and the overall runoff direction is from the land to the surrounding sea area.

According to the regional geological data and on-site hydrogeological mapping, there is a fault passing through the plant site (the F1 fault in figure 1). Its occurrence is $142<35^{\circ}$.

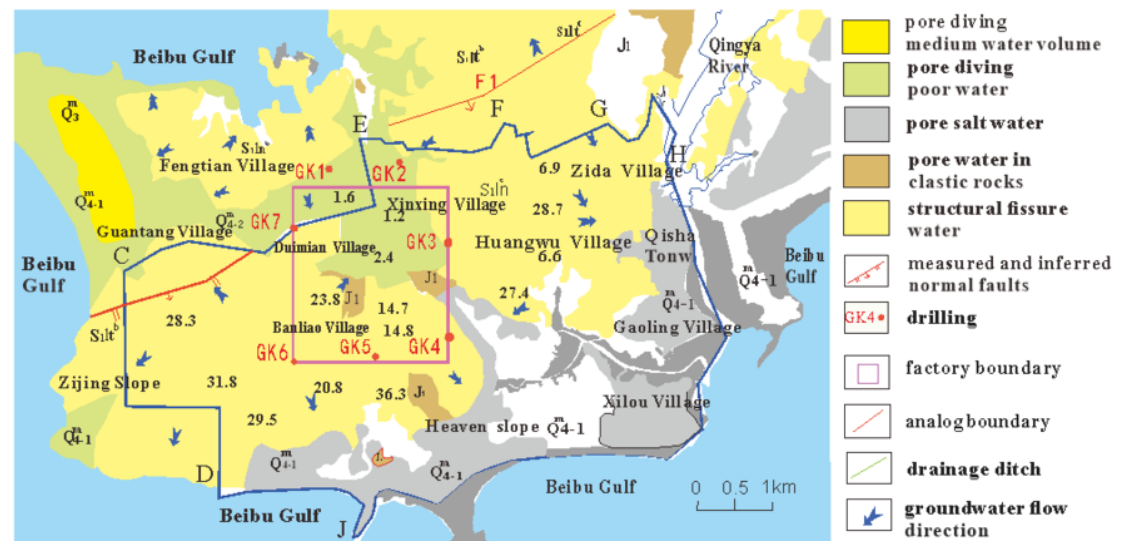

Figure 1. Regional hydrogeological map.

Influence of sea tide on groundwater flow field: Based on the measured water level data of 98 observation points of groundwater level in the study area in 2018, the contour map of wet, normal, and dry seasons is drawn. From these maps, it was found that only in the areas where the groundwater level is higher than $2.0 \mathrm{~m}$ can the groundwater isoline be drawn. The water level below $2.0 \mathrm{~m}$ is disordered and irregular, and it is impossible to draw $1.5 \mathrm{~m}, 1.0 \mathrm{~m}$, and $0.5 \mathrm{~m}$ isolines in the map. This phenomenon indicates that the area with below $2.0 \mathrm{~m}$ groundwater level were affected by lifting effect of the sea tide. It is because of the sea tide jacking effect that the direction of groundwater flow is uncertain. 


\section{Numerical Simulation of Groundwater Flow Field}

The mathematical model is as follows [3].

$$
\left\{\begin{array}{lc}
\frac{\partial}{\partial x}\left[K_{x} \frac{\partial h}{\partial x}\right]+\frac{\partial}{\partial y}\left[K_{y} \frac{\partial h}{\partial y}\right]+\frac{\partial}{\partial z}\left[K_{z} \frac{\partial h}{\partial z}\right]+W=\mu_{s} \frac{\partial h}{\partial t} \quad(x, y, z \in \Omega) \\
h(x, y, z, t)=h_{0}(x, y, z) & (x, y, z \in \Omega), t=0 \\
h \mid B_{1}=h_{1}(x, y, z, t) & (x, y, z) \in B_{1}, t \geq 0 \\
k \frac{\partial k}{\partial \vec{n}} \mid B_{2}=q(x, y, z, t)=0 & (x, y, z) \in B_{2}, t \geq 0
\end{array}\right.
$$

where: $h$-groundwater of head (m); $K_{x}, K_{y}$ and $K_{z}$-permeability coefficients in $x, y, z$ directions $(\mathrm{m} / \mathrm{d}) ; B_{1}$ - known head boundary (type I boundary); $B_{2}$-water separation boundary; $h_{12}$-river level $(\mathrm{m}) ; W$-source sink term strength $\left(\mathrm{d}^{-1}\right) ; \Omega$-seepage area; $\mu_{s}$ - storage rate $\left(\mathrm{m}^{-1}\right)$, which is taken as 0.0005 according to empirical values.

\subsection{Boundary Conditions}

Plane boundary: The drainage ditch (CD section in figure 1), the coastline on the south (DJI section), the Xialuo River on the north (CE and EF, GH) are all the first-type boundaries in numerical simulation. The FGH section is surface watershed, is treated as the second kind of boundary (impermeable boundary).

Moving boundary: Due to the sea tide fluctuation, some first-type boundary lines change from time to time, so they must be served as the moving boundaries and their position is determined according to the contour in the topographic map at different times [3].

Vertical boundary: The upper interface of the aquifer is bounded by the water table, which is the free boundary, its height is obtained from the measured water level and interpolation. The bottom boundary of the aquifer is the top of the slightly weathered bedrock (argillaceous sandstone and mudstone), it is also the second boundary in simulation.

\subsection{Generalization of the Model}

The aquifer is divided into three following layers: loose silty clay layer (the first layer), strongly weathered siltstone layer (the second layer) and moderately strongly weathered (the third layer).

\subsection{Hydrogeological Parameters}

Determined the initial value: (1) The surface soil is silty clay, so the rainfall infiltration coefficient is $0.10 \mathrm{md}^{-1}$ in dry season, $0.09 \mathrm{md}^{-1}$ in normal season and $0.07 \mathrm{md}^{-1}$ in wet season; (2) The permeability coefficient of the aquifer is given an initial value based on the results of the borehole injection test.

Reverse calculation of parameters: The groundwater level and sea water level values obtained from seven times of observation in the survey area are input into the model, and the groundwater level of each observation point is fitted according to the unsteady flow by adjusting the relevant parameters. When the best fitting effect is achieved, the hydrogeological parameters and parameter zoning are obtained. The 
fitting situation is shown in figure 2 .

\subsection{Discretization of Model}

There are 100 rows and 100 columns on the simulation plane, totaling 10,000 rectangular cells. The terrain elevation is input into the model in the form of hash points, and then the IDW interpolation method is used for assignment. The resulting terrain map is shown in figure 3 [4]. The simulation also needs to discretize the time. In order to deal with the moving boundaries under the influence of sea tide, the simulation period is set as $6 \mathrm{~h}$.

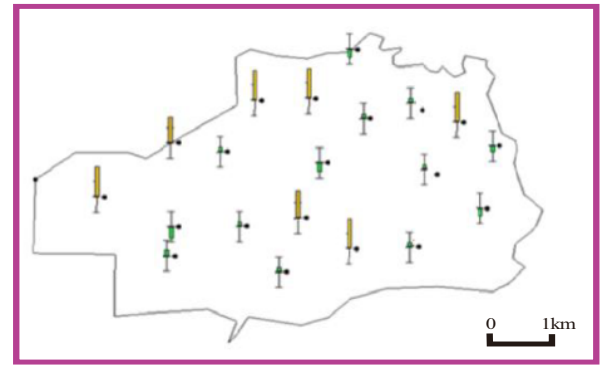

Figure 2. Fitting diagram of some monitoring points.

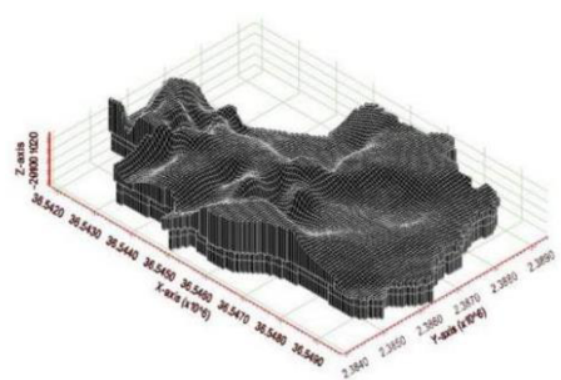

Figure 3. 3D dissection of simulation area.

\section{Solute Transport Model and Groundwater Prediction}

\subsection{Solute Transport Model}

Three-dimensional hydrodynamic dispersion mathematical model [5-6]:

$$
\frac{\partial C}{\partial x_{i}}\left(D_{i j} \frac{\partial C}{\partial x_{j}}\right)-\frac{\partial}{\partial x_{i}}\left(v_{i} C\right)+\frac{q_{s}}{\theta} C_{s}-\lambda\left(C+\frac{\rho_{b}}{\theta} \bar{C}\right)=R \frac{\partial C}{\partial t}
$$

Initial condition:

$$
C(x, y, t)=C_{0}(x, y)(\mathrm{x}, \mathrm{y}) \in \Omega, \mathrm{t}=0
$$

The first kind of boundary conditions:

$$
\left.C(x, y, t)\right|_{\Gamma_{1}}=C(x, y, t) \quad(\mathrm{x}, \mathrm{y}) \in \Gamma_{1}, \mathrm{t} \geq 0
$$

The third kind of boundary conditions:

$$
\left(\theta D_{i j} \frac{\partial C}{\partial x_{j}}-q C\right) \Gamma_{\Gamma_{3}}=g_{i}(x, y, t) \quad(\mathrm{x}, \mathrm{y}) \in \Gamma_{3}, \mathrm{t} \geq 0
$$


In the above equations: $C$ - contaminant concentration dissolved in water $\left(\mathrm{M} / \mathrm{L}^{3}\right)$; $D_{i j}$-hydrodynamic dispersion coefficient tensor $\left(\mathrm{L}^{2} / \mathrm{T}\right) ; X i$-spatial coordinate $(\mathrm{L})$; $v_{i}$-groundwater infiltration flow rate $(\mathrm{L} / \mathrm{T}) ; q_{s}$ - unit flow rate of source (positive) or sink (negative) (1/T); $\theta$ - porosity, dimensionless; $C s$ - concentration of source or sink $\left(\mathrm{M} / \mathrm{L}^{3}\right) ; \lambda$-order reaction rate constant $(1 / \mathrm{T}) ; \rho_{b}$-gravity of porous medium $\left(\mathrm{M} / \mathrm{L}^{3}\right)$; $\bar{c}$ — contaminant concentration adsorbed on medium $(\mathrm{M} / \mathrm{M}) ; R$-retardation factor, dimensionless; t-time, d.8

The power dispersion coefficient was determined by referring to similar previous empirical results [7], and the present longitudinal dispersion was taken as $0.006 \mathrm{~m}$. The transverse dispersion was taken as $1 / 8$ of the longitudinal dispersion to take the empirical value [8].

\subsection{Aluminum Oxide Project Wastewater Treatment Facility Accident Results Prediction}

The volume of the regulating pool in the wastewater treatment station is $30 \times 36 \times 10 \mathrm{~m}$, and its wetted area is $2400 \mathrm{~m}^{2}$. Assuming that the seepage rate is $4.8 \mathrm{~m}^{3} / \mathrm{d}$ and the leakage accident is found and treated 30 days after the accident. According to the surface soil permeability coefficient of 0.2 , the total amount of waste water leakage into the underground is $28.8 \mathrm{~m}^{3}$. Based on the sewage components and concentration values provided in the feasibility research report of the project, the selected prediction factors are fluoride $\left(\mathrm{F}^{-}\right)$and $\mathrm{COD}$, and their initial concentrations (source intensity) are $9.46 \mathrm{mg} / \mathrm{L}\left(\mathrm{F}^{-}\right)$and $250 \mathrm{mg} / \mathrm{L}(\mathrm{COD})$ respectively.

\subsubsection{Prediction of COD Pollution Halo Migration}

The COD concentration of $3.0 \mathrm{mg} / \mathrm{L}$ (Class III groundwater quality standard) is taken as the dividing line of pollution halo. COD can be degraded under the action of microorganisms in the aquifer. According to the current research, the speed of COD degradation is in accordance with the law of first-order reaction kinetics. That is, the COD degradation rate question is [9]:

$$
C_{t}=C_{0} \cdot e^{-k t}
$$

where: $C_{t}$ is the COD concentration at time t, $\mathrm{mg} / \mathrm{L} . C_{0}$ is the initial concentration of COD infiltration into the aquifer, $\mathrm{mg} / \mathrm{L}$; $t$ is the time of COD staying in the aquifer, $\mathrm{d} ; k$ is the attenuation rate coefficient, $\mathrm{d}$.

According to the results of many experiments so far, the decay rate coefficient $\mathrm{k}$ is related to many factors such as water temperature, initial COD concentration, the concentration of inorganic reducing substances such as sulfur ammonia, and the content of dissolved oxygen (DO). In general, the decay rate coefficient $\mathrm{k}=0.023 \sim 0.086 \mathrm{~d}^{-1}$ in the surface environment [10]. Considering the low water temperature and dissolved oxygen content in the aquifer of the study area, $\mathrm{k}=0.004 \mathrm{~d}$ - (equivalent to $5.75 \sim 21.5$ times slower than the decomposition rate in the atmosphere) is used to simulate.

The prediction results of COD pollution halo in aquifer by GMS are shown in table 1.

\subsubsection{Forecast of Fluoride Pollution Halo Migration}

The prediction results are shown in figure 4 and table 1 . 
Table 1. COD and $\mathrm{F}$ diffusion characteristics in the aquifer.

\begin{tabular}{lllll}
\hline \multirow{2}{*}{$\begin{array}{l}\text { Time after } \\
\text { leakage }\end{array}$} & \multicolumn{2}{l}{ COD } & \multicolumn{2}{l}{ F } \\
\cline { 2 - 5 } & Downward migration Center concentration of & Downward migration Center concentration \\
distance $(\mathbf{m})$ & COD $(\mathbf{m g} / \mathbf{L})$ & 67.95 & 0.25 \\
\hline $100 \mathrm{~d}$ & 87.48 & 69.04 & 219.5 & 0.89 \\
\hline $1000 \mathrm{~d}$ & 2.52 & 3.05 & 297.27 & 1.96 \\
\hline $10000 \mathrm{~d}$ & 0 & 2.7 (background value) & \\
\hline
\end{tabular}
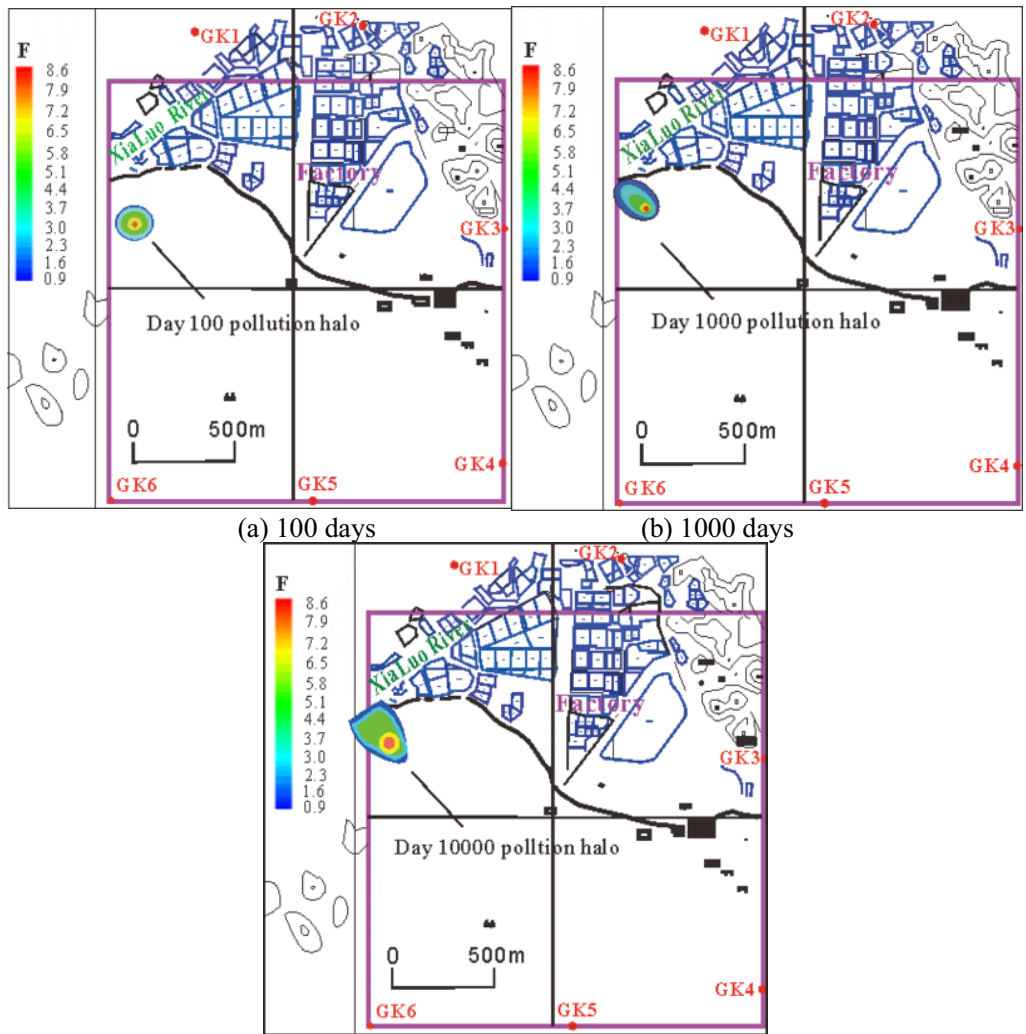

(c) 10000 days

Figure 4. Migration diagrams of contaminated halos at $100 \mathrm{~d}, 1000 \mathrm{~d}$ and $10000 \mathrm{~d}$ after the leakage of $\mathrm{F}$ in aquifer

Table 1 shows that after the leakage accident, the pollution of the groundwater environment in the study area shows different characteristics from other places, that is, the concentration of $\mathrm{F}$ in the pollution center will increase with time. After analyzing this unusual phenomenon, it is believed that this is mainly caused by the jacking effect of seawater. Because the groundwater flow at the leakage point is basically in a stagnant state under the action of sea tide jacking, it is difficult for pollutants to migrate downstream. With the passage of time, more and more pollutants infiltrate from the vadose zone, which makes the pollutants in the aquifer under the leakage point accumulate more and more, and makes the concentration of the pollution halo center become higher and higher with the passage of time. 


\section{Conclusion}

(1) The simulation results show that the leakage sewage under abnormal condition will seeped into groundwater and diffuse northward, and finally discharge to Xialuo river. However, because there is no pumping well between the leakage point and Xialuo river, the leakage accident will not affect the drinking water of the surrounding residents.

(2) After a spill, the concentration at the center of pollution halo will increase with time. This unusual phenomenon is mainly due to the low permeability of the local water bearing medium and the jacking effect of seawater on the groundwater flow field.

\section{Acknowledgements}

This work was support by the National Natural Science Foundation of China (No.41877194).

\section{References}

[1] Dong Y W, Yu Q C and Zheng Y H 2018 Study on prediction and evaluation of groundwater environmental impact of coastal chemical enterprises based on numerical simulation model Groundwater 40 (3) 19-22.

[2] Zuo R, Wang J S, Yang J, et al. 2010 Key issues of groundwater environmental impact assessment for coastal petrochemical projects Hydrogeology and Engineering Geology 37 (3) 97-101.

[3] Wu Y, Yang Z, Cheng C, et al. 2020 Study on the influence of tidal fluctuation on the intrusion pattern of seawater in submerged aquifers Journal of Ocean University of China 50 (10) 091-098

[4] Liang Y M and Lan J K 2019 Prediction of groundwater pollution caused by sulfuric acid tank leakage based on GMS simulation Journal of Guilin University of Technology 39 (1) 190-196.

[5] Feng L W and Gao L 2020 Groundwater numerical simulation of yuba water source based on GMS software Journal of Zhejiang University of Water Resources and Hydropower 32 (4) 11-13.

[6] Cheng Y P, Hong S N, Lan J K, et al. 2015 Prediction and evaluation of groundwater pollution of zinc sulfate construction project in Qinzhou Environmental Science and Technology 38 (4) 176-182.

[7] Yu H, Guo K, Luo Q B, et al. 2016 Field dispersion test of submerged aquifers in northeastern Dingbian Environmental Chemistry 35 (3) 9-17.

[8] Zhang Y F, Zhang X Y, Xu Y H, et al. 2003 Research development of hydrodynamic dispersion coefficient in soils Environmental Pollution Control Technology and Equipment 4 (7) 8-12.

[9] Yun F, Li Y, Yang J N, et al. 2005 Discussion on the simulation of the dynamic distribution of COD and ammonia nitrogen pollution in the Ningxia section of the Yellow River Journal of Ningxia University 3 (26) 283-286.

[10] Guo R, Li Y B and Fu G 2008 Analysis of factors influencing the attenuation coefficient of pollutants in rivers Journal of Meteorology and Environment 24 (1) 56-59. 